\title{
Biodiversity and ecosystem functioning in a species-poor guild: a test using tropical stream detritivores
}

\author{
David Dudgeon • Becky W. Gao
}

Received: 2 March 2010/Revised: 13 June 2010/Accepted: 19 June 2010/Published online: 1 July 2010

(C) The Author(s) 2010. This article is published with open access at Springerlink.com

\begin{abstract}
The relationship between biodiversity and ecosystem functioning (B-EF) was investigated by examining top-down effects of aquatic detritivore diversity on the functional process of leaf-litter breakdown. This study was undertaken in tropical Hong Kong where the stream detritivore guild is depauperate and loss of one or a few species might have strong effects on processes. Effects of detritivore richness and composition were investigated by comparing feeding rates of three species of detritivores with their two- and three-species mixtures in laboratory trials. The detritivores were a caddisfly larva (Anisocentropus maculatus: Calamoceratidae), a snail (Brotia hainanensis: Pachychilidae) and a shrimp (Caridina cantonensis: Atyidae). Liquidambar formosana (Hamamelidaceae) litter was provided as food. All three detritivore species had positive non-additive effects on litter processing. Per capita and mass-specific feeding rates of each species were faster in mixtures than when they were alone, although the non-additive effects of shrimps and snails were larger than those attributable to caddisflies, and thus, litter processing was strongly
\end{abstract}

Handling editor: S. Stendera

D. Dudgeon $(\bowtie) \cdot$ B. W. Gao

Division of Ecology and Biodiversity,

School of Biological Sciences,

The University of Hong Kong, Hong Kong SAR, China

e-mail: ddudgeon@hkucc.hku.hk influenced by the composition of detritivore mixtures. The compositional effect appears to be evidence of facilitation indicating a lack of functional redundancy amongst these detritivores, probably due to their evolutionary distinctness, implying that extinction consequences in this species-poor guild will depend on the identity of the species lost.

Keywords Litter breakdown · Shredders · Hong Kong · Species loss · Detritus

\section{Introduction}

The nature of the relationship between biodiversity and ecosystem functioning (B-EF) is a key question for ecologists and conservation biologists, because the need to sustain ecosystem function has been used as a justification for preserving biodiversity and preventing species loss (e.g. Naeem et al., 1994; Loreau et al., 2001). Although there is evidence that ecosystem processes can be impacted by changes in biodiversity (Covich et al., 2004; Hooper et al., 2005) the dynamics of the B-EF relationship, and hence the consequences of species loss, is not well understood (Loreau et al., 2001). This is a matter of particular concern in fresh waters where threats to biodiversity are greater than in the terrestrial or marine realms (Dudgeon et al., 2006). Declines in diversity will tend to be non-random, because some species are more 
vulnerable than others, making B-EF vulnerable both to reductions in richness and changes in composition (Naeem et al., 1994; Jonsson et al., 2002; Covich et al., 2004).

Most B-EF research in fresh waters involves studies of organic-matter processing (Giller et al., 2004; Kominoski et al., 2010), especially the dynamics of leaf-litter breakdown mediated by shredding detritivores in streams (e.g. Jonsson et al., 2001, 2002; Gessner \& Chauvet, 2002; Lecerf \& Richardson, 2010). Investigations of the top-down effects of detritivores show that increased richness often accelerates litter breakdown, but additive effects (essentially predictable from the combined effects of the species in the mixture) and non-additive effects (unpredictable, perhaps due to redundancy amongst species or facilitation) are both possible (e.g. Jonsson \& Malmqvist, 2000, 2003; Jonsson et al., 2002; Boyero et al., 2007). Even when a similar range of richness variation is considered, different B-EF relationships have been recorded, indicating that multiple mechanisms are likely to underlie observed relationships (McKie et al., 2008). However, a recent meta-analysis (Lecerf \& Richardson, 2010) suggests that non-additive or compositional effects of detritivores and effects of species identity have more important influences on B-EF than species richness per se (Kominoski et al., 2010; but see Jonsson et al., 2001). Investigations of other B-EF relationships in fresh waters (e.g. McIntyre et al., 2007) and some results from other ecosystems (Hooper et al., 2005; Cardinale et al., 2006) imply the same pattern of compositional effects.

Most B-EF investigations of stream detritivores have used species within the same order (mainly Plecoptera: e.g. Jonsson \& Malmqvist, 2000) or phylum (e.g. Insecta, usually Plecoptera and Trichoptera: e.g. Boyero et al., 2007), although more evolutionarily distinct mixtures have been studied in a few instances (e.g. Insecta and Crustacea: Jonsson et al., 2002; McKie et al., 2008). Diversity of obligate or facultative shredding detritivores (sensu Jonsson et al., 2001) in many tropical streams appears to be low (reviewed by Jacobsen et al., 2008). For example, benthic samples from ten Hong Kong streams yielded a total of eight species of shredders, with only three to six species at each site but including representatives of three phyla (Li \& Dudgeon, 2008a, 2009). This compares with a total of 26 shredders (up to 11 species per site), mainly Plecoptera and Trichoptera, recorded in a survey of 23 Swedish streams (Jonsson et al., 2001). Whilst the paucity of detritivore species in Hong Kong limits the range of combinations for B-EF investigations, the range of phyla represented (crustaceans, molluscs and insects) offers the opportunity to examine interactions between more distantly related detritivores than have been included in previous studies. This allowed us to test the notion that species loss and changes in B-EF will be more apparent when distantly related but functionally similar taxa are affected (Jonsson et al., 2002; see also Giller et al., 2004; McKie et al., 2008) by comparing our results with studies of closely related detritivores that have greater potential for functional redundancy.

Our specific objectives were to determine whether litter breakdown rates varied between treatments including single or multiple species of disparate detritivores and, where a diversity effect was detected, to assess whether the effect was due to increased species richness or the species composition of mixtures. In addition, where compositional effects were detected, and the combined effects of detritivore species were complementary rather than simply additive, we estimated the relative contribution made by each species to the overall non-additive effect.

\section{Methods}

Study species

Diversity effects of detritivores on litter breakdown rate were investigated in a laboratory feeding experiment using three species of detritivores in different phyla (Insecta, Mollusca and Crustacea). They were Anisocentropus maculatus Ulmer 1926 (Trichoptera: Calamoceratidae) and Brotia hainanensis (Bröt 1872) (Gastropoda: Pachychilidae), which are, respectively, the most abundant obligate and facultative shredders in Hong Kong streams (Li \& Dudgeon, 2008a), and Caridina cantonensis Yu 1938 (Decapoda: Atyidae). This shrimp is likewise locally widespread, and feeds on litter in the field and the laboratory, skeletonising palatable species (Yam \& Dudgeon, 2006; Lau et al., 2009). All three detritivores co-occur in Hong Kong streams, but their relative abundance varies amongst sites. Liquidambar formosana Hance (Hamamelidaceae) 
litter was chosen for this study because it is eaten readily by all three detritivores (Dudgeon, 1982; Li \& Dudgeon, 2008b; Lau et al., 2009). Abscised leaves of L. formosana were collected from Tai Po Kau Nature Reserve $\left(22^{\circ} 24^{\prime} \mathrm{N}, 114^{\circ} 11^{\prime} \mathrm{E}\right)$ in October 2007 and air-dried to constant weight in the laboratory.

Detritivores were collected from stony streams (mainly in Tai Po Kau Forest) between 3 and 10 April 2008 and transported to the laboratory in aerated stream water. There they were acclimated for at least 3 days and fed on a mixture of conditioned litter (excluding L. formosana). Similar-sized individuals of each species were used in the experiment: caddisflies with ventral case length of 10.0-14.0 mm (mainly fourth-instar larvae: Li \& Dudgeon, 2008b); snails with shell apertures of 9.1-10.0 mm; and shrimps with carapace length of 4.6-6.0 mm. Measurements were made with Mitutoyo digital calipers $( \pm 0.1 \mathrm{~mm}$ for caddisflies and snails) or a stereomicroscope $(10 \times$ magnification) fitted with a micrometre eyepiece $( \pm 0.05 \mathrm{~mm}$ for shrimps).

\section{Experimental arrangement}

Feeding trials were conducted in plastic chambers $(18 \mathrm{~cm} \times 12 \mathrm{~cm} \times 8 \mathrm{~cm})$ containing $7.00 \pm 0.01 \mathrm{~g}$ air-dried leaves and 11 of stream water that was aerated continuously. Chambers were organized in blocks of eight treatments consisting of seven diversity treatments (with different combinations of detritivores) and one control treatment (without detritivores). The seven diversity treatments comprised three single-species treatments, three-two-species treatments (all possible pair-wise combinations) and one-three-species treatment. This arrangement was replicated six times resulting in 48 chambers arranged in six randomized blocks. Photoperiod was maintained at $12: 12$, and water temperatures averaged $22.7^{\circ} \mathrm{C}$ (range: $21.2-23.8^{\circ} \mathrm{C}$ ).

After a 14-day period to allow for leaf conditioning, the feeding trials began with the addition of detritivores to each chamber (except the controls): 12 individuals of the same species for the single-species treatments, six individuals of each species for the two-species treatments and four individuals of each species for the three-species treatment. Each chamber was checked daily during the trials, and any dead detritivores or pupated caddisflies were replaced by new individuals. Half the water in each chamber was changed every other day. Feeding trials were terminated after 14 days. Litter was gently rinsed in tap water, oven-dried at $60^{\circ} \mathrm{C}$ for $48 \mathrm{~h}$, and weighed to yield dry mass (DM). Three samples of litter from each treatment were ashed at $500^{\circ} \mathrm{C}$ for $4 \mathrm{~h}$ in a furnace (Barnstead Thermolyne 30400) and reweighed to obtain ash-free dry mass (AFDM) for calculating DM-to-AFDM conversion factors. Three samples of air-dried leaves were likewise dried and ashed to obtain conversion factors from initial air-dry mass to initial AFDM. Final AFDM of all detritivores was obtained by the same procedure after dissection to remove snail shells and gut contents.

Data analysis

Differences in final AFDM of each detritivore species in the single- and multiple-species treatments were examined by one-way ANOVA followed by Dunnett's tests with the mean AFDM of each species in each chamber taken as replicates. Data on litter mass loss (LML), corrected for non-detritivorecaused LML in controls, were used to test for interspecific differences in litter processing rates amongst treatments by one-way ANOVA and a StudentNeuman-Keuls post hoc test. Data were analysed in terms of both mass-specific (AFDW) and per capita LML for each species.

Diversity effects (richness and species composition) of detritivores on LML were investigated using a three-way, type-I sum of squares (SS) ANOVA (Schmid et al., 2002) with blocks and detritivore species richness as two fixed factors, and composition (i.e. the species present in each treatment) nested within richness, thereby splitting the diversity term (following Ball et al., 2008). The percentage sum of squares (\%SS) was reported as a surrogate of the proportion of total variance explained by composition and richness.

A full-factorial ANOVA including all possible species mixtures was used to test for non-random changes in detritivore diversity and detection of nonadditive effects on LML (following Jonsson et al., 2002; see also Kominoski et al., 2010). The block term, the three detritivore species terms, and a species interaction term were added sequentially to the model. Each species term (two levels: present and absent) was included as a main effect in the model, 
and the species interaction term (three levels) was the sum of any possible pair-wise interactions of the main effects. A significant value of the species interaction term indicated a particular species mixture had nonadditive effects, and a significant result for a particular detritivore indicated whether it contributed to that effect.

The occurrence of any non-additive effects arising from species mixtures was detected by comparing treatment-specific observed (O) and expected (E) LML by paired $t$-tests for each detritivore species. $\mathrm{O}$ values were measured directly for each treatment, whereas treatment-specific $E$ values were derived from the mean LML caused by the component species when in single-species treatments. Further analysis of the magnitude of non-additive effects associated with a particular detritivore involved comparing $\mathrm{O}$ and $\mathrm{E}$ LML attributable to each species in multiple-species treatments using paired $t$-tests (Ball et al., 2008). $\mathrm{O}$ values in multiple-species treatments were derived directly from the per capita LML of each species in that treatment. Species-specific E values for the three-species treatment were calculated as the average of the LML for each species in the single-species treatments and in the two-species treatments containing one or other of the two detritivore species. E values for the two-species treatment were derived from the mean per capita LML of each species in single-species treatments.

All statistical analyses were carried out using SAS 9.0 (SAS Institute Inc., Cary, NC, USA), except for paired $t$-tests conducted with SPSS 16.0 (SPSS Inc., Chicago, IL, USA). Logarithmic and arcsine transformations (for detritivore AFDM and $\%$ LML, respectively) were applied prior to these analyses.

\section{Results}

No detritivore mortality occurred during the feeding trials, but $22 \%$ of caddisflies pupated and were replaced during the experiment. Final AFDM of all three detritivore species tended to be greater in multiple-species treatments than in single-species treatments (Table 1). However, the difference was significant for shrimps only (ANOVA: $F_{3,20}=19.5$, $P<0.0001$ vs. $F_{3,20} \leq 2.7, P \geq 0.08$ for the other two species), which were $2.7-4.1 \mathrm{mg}$ AFDW ind $^{-1}$ heavier in two- and three-species treatments than in the single-species treatment. Mass-specific LML rates attributable to detritivores varied significantly amongst single-species treatments (ANOVA: $F_{2}, 15$ $=316.0, P<0.0001)$ declining in the sequence $A$. maculatus (caddisflies) $>B$. hainanensis (snails) $>$ C. cantonensis (shrimps). The same general pattern was seen when results were expressed in LML per capita (ANOVA: $F_{3,15}=138.2, P<0.0001$; Fig. 1) although the difference between snails and caddisflies was minor. Only analyses of per capita LML data are presented herein, since the initial litter mass in each treatment was the same and three-way and fullfactorial ANOVAs of LML in per capita and massspecific terms yielded the same outcomes.

Three-way ANOVA to investigate the relative contribution of richness and composition to diversity effects of detritivores (Table 2) indicated that treatment effects were due predominately to species composition (84.7\% variance explained; $P<0.0001)$; the variance explained by species richness was small (8.2\%; $P>0.05)$. A significant species interaction term in the full-factorial ANOVA indicated that all three detritivores had non-additive effects on LML (Table 3). These results were in general agreement with the finding that $\mathrm{O}$ LML rates exceeded $\mathrm{E}$ in all multiple-species

Table 1 Mean final AFDM (mean \pm SE) of individuals of the three detritivore species across chambers in each treatment

\begin{tabular}{|c|c|c|c|c|c|}
\hline Species & Single species & $A+B$ & $\mathrm{~A}+\mathrm{C}$ & $\mathrm{B}+\mathrm{C}$ & $\mathrm{A}+\mathrm{B}+\mathrm{C}$ \\
\hline A. maculatus (A) (caddisfly) & $3.2 \pm 0.1$ & $3.4 \pm 0.1$ & $3.5 \pm 0.1$ & - & $3.9 \pm 0.3$ \\
\hline B. hainanensis (B) (snail) & $31.3 \pm 0.5$ & $33.8 \pm 1.1$ & - & $32.8 \pm 0.8$ & $33.1 \pm 1.1$ \\
\hline C. cantonensis (C) (shrimp) & $12.9 \pm 0.1$ & $16.3 \pm 0.4^{*}$ & - & $15.6 \pm 0.7 *$ & $16.9 \pm 0.3 *$ \\
\hline
\end{tabular}

Asterisk $(*)$ indicates a significant difference from the single-species treatment at $P<0.05$ 


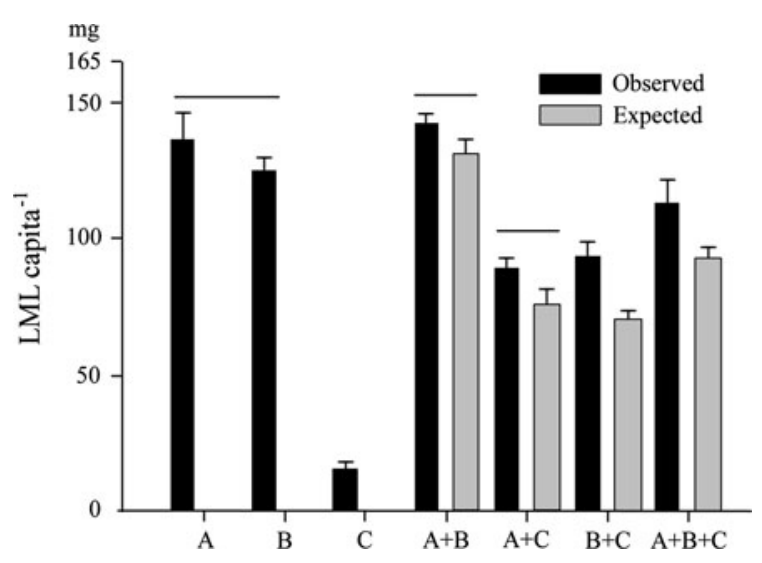

Fig. 1 Per capita LML (mg AFDW LML; mean \pm SE) attributable to detritivores in all treatments; expected LML values for multiple-species treatments are shown also. Horizontal bars indicate no difference at $P=0.05$. $\mathrm{A}=$ A. maculatus (caddisfly), $\mathrm{B}=B$. hainanensis (snail) and $\mathrm{C}=$ C. cantonensis (shrimp)

Table 2 Three-way ANOVA using type-I sum of squares (SS) for detecting the contribution of detritivore species richness and composition to diversity effects on per capita LML

\begin{tabular}{lrlrlrr}
\hline Effect term & df & SS & \%SS & MS & \multicolumn{1}{l}{$F$} & \multicolumn{2}{l}{$P$} \\
\hline Block & 5 & 0.0009 & 1.6 & 0.0002 & 1.71 & 0.1619 \\
Species richness & 2 & 0.0045 & 8.2 & 0.0023 & 0.19 & 0.8305 \\
Species & 4 & 0.0466 & 84.7 & 0.0117 & 115.73 & $<0.0001$ \\
$\quad$ composition & & & & & & \\
Error & 30 & 0.0030 & 5.5 & 0.0001 & & \\
Total & 41 & 0.0550 & & & & \\
\hline
\end{tabular}

Table 3 Summary of full-factorial ANOVA to test for nonrandom changes in diversity and detection of non-additive effects of detritivore species on per capita LML

\begin{tabular}{lrlrlrr}
\hline Effect term & df & SS & \multicolumn{1}{l}{$\%$ SS } & MS & \multicolumn{1}{l}{$F$} \\
\hline Block & 5 & 0.0009 & 1.6 & 0.0002 & 1.71 & 0.1619 \\
A. maculatus & 1 & 0.0138 & 25.0 & 0.0138 & 137.45 & $<0.0001$ \\
B. hainanensis & 1 & 0.0173 & 31.5 & 0.0173 & 171.31 & $<0.0001$ \\
C. cantonensis & 1 & 0.0093 & 16.9 & 0.0093 & 92.78 & $<0.0001$ \\
Species & 3 & 0.0107 & 19.5 & 0.0036 & 35.48 & $<0.0001$ \\
$\quad$ interaction & & & & & & \\
Error & 30 & 0.0030 & 5.5 & 0.0001 & & \\
Total & 41 & 0.0550 & & & & \\
\hline
\end{tabular}

treatments, although the difference was statistically significant only in the two treatment mixtures including both snails and shrimps (Fig. 1). Comparison of $\mathrm{O}$ versus $\mathrm{E}$ LML rates attributable to each detritivore species in multiple-species treatments relative to the single-species treatment confirmed that they all exhibited significantly faster than expected processing rates when in the presence of any one or both of the other species, but this difference was less strongly significant for caddisflies $(t=-2.18, P=0.043)$ than for snails $(t=-2.62, P=0.002)$ or shrimps $(t=-3.66, P=$ 0.002 ), in accordance with the relatively large nonadditive effects seen in the two treatments that included both snails and shrimps (Fig. 1). Non-additive effects attributable to caddisflies in each multiple-species treatment were positive but small and statistically insignificant $\quad\left(t_{5} \leq-2.16 ; \quad P \geq 0.083 ; \quad\right.$ Fig. 2a), whereas LML was faster than expected in the pairing of snails and shrimps $\left(t_{5}=-3.31 ; P=0.021\right)$ where both species contributed to the non-additive effect (Fig. 2b, c), and in the mixture of all three detritivore species $\left(t_{5}=-2.62 ; P=0.047\right.$; see also Fig. 1$)$. This combined effect was significant even though the increase in LML attributable to each of the three species was too small to be statistically significant (Fig. 2).

\section{Discussion}

Biodiversity and ecosystem functioning effects on LML attributable to due to three disparate detritivore species from Hong Kong streams were non-additive, and influenced more strongly by the composition of a mixture than by its richness. This accords with the findings of Jonsson et al. (2002) who recorded compositional effects associated with three taxonomically distinct species (a stonefly, a caddisfly, and an amphipod), and with Boyero et al. (2007) who combined three shredding caddisflies with a mayfly. Comparisons of mixtures of insect species with and without amphipod crustaceans likewise tended to show biodiversity effects only in disparate mixtures containing two phyla (McKie et al., 2008). However, none of these studies included a range of taxa comparable to the present investigation. In contrast, investigations of B-EF that have included closely related species tended to report an effect of richness but not composition on litter processing when, for instance, mixtures were made up only of species of caddisflies (Boyero et al., 2007; McKie et al., 2008) or stoneflies (Jonsson \& Malmqvist, 2000). The greater range of feeding behaviour manifested by 

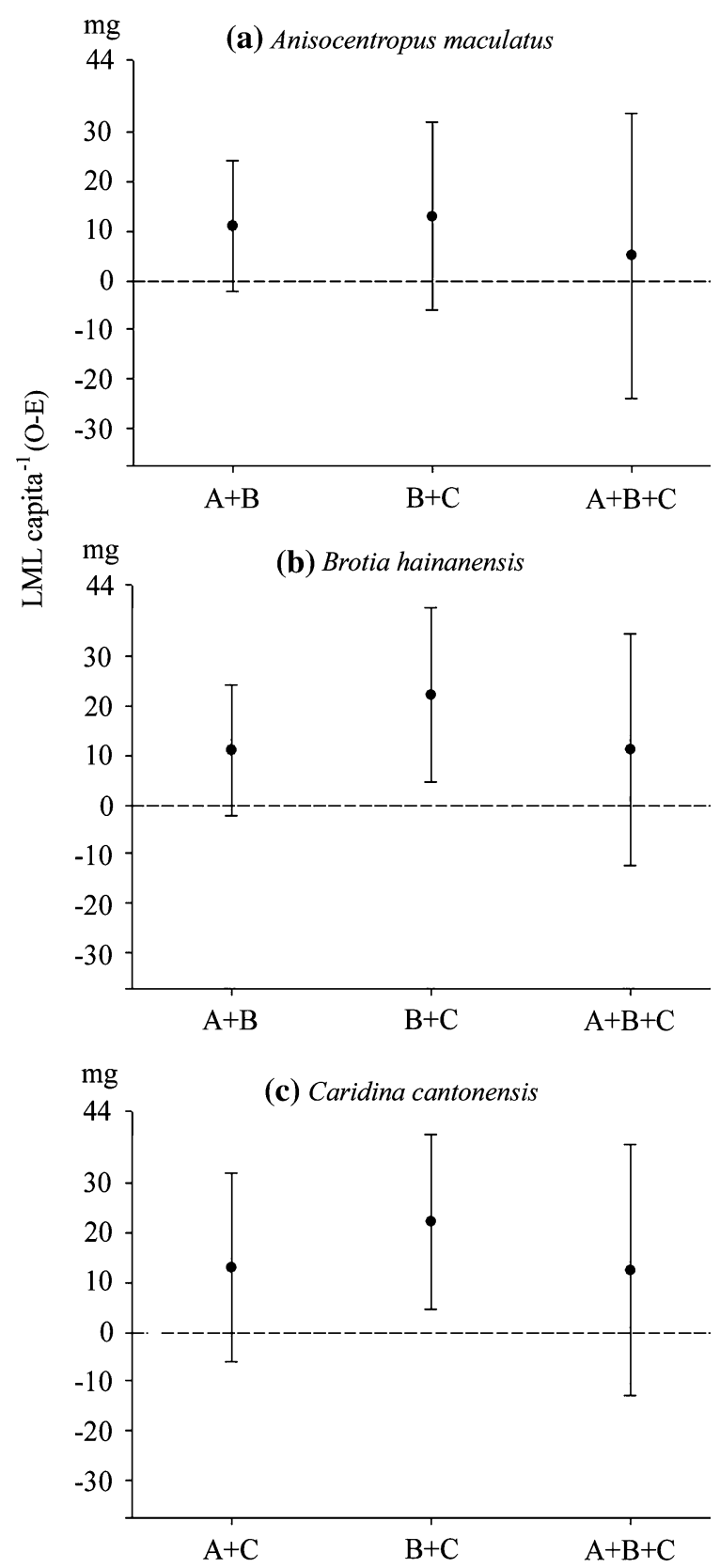

Fig. 2 Mean differences between observed (O) and expected (E) LML per capita (O-E) for each detritivore species in multiple-species treatments. Error bars $(95 \%$ confidence intervals) that do not cross the no-difference line indicate a significant non-additive effect of the detritivore species in that multiple-species mixture. For abbreviations, see Fig. 1

more disparate taxa probably increases the potential for facilitation and/or complementary use of the litter resource (Giller et al., 2004; McKie et al., 2008). This would seem likely in this study where feeding modes consisted of biting and chewing (the caddisfly, $A$. maculatus), radular scraping (the snail, $B$. hainanensis) and chelar brushing (the shrimp, C. cantonensis), and where FPOM produced by snails and caddisflies during feeding could have been collected and eaten by shrimps. Studies of inter-specific facilitation in mixtures of six stonefly species suggest that acceleration of LML is most marked when 3 species or fewer are mixed, when facilitation '.. is more likely to be species specific with species identities being more important than species richness per se' (Jonsson $\&$ Malmqvist, 2003, p. 554). Our results support this conclusion about the importance of species identities at low levels of richness, and the compositional (species-specific) effect we observed is likely to have been enhanced by the inclusion of disparate taxa with diverse feeding modes.

A notable outcome of the compositional effect on litter breakdown rates was the substantial $36 \%$ increase in LML (relative to that expected) in the two-species mixture of snails and shrimps, compared to the $24 \%$ increase observed in the three-species mixture. This exceeded the largest non-additive effects (up to $24 \%$ increase in per capita LML) occurring in mixtures of stoneflies and/or caddisflies (Jonsson \& Malmqvist, 2000; Boyero et al., 2007) although, in those studies, effect sizes were not attributed to particular component species. LML seemed to be faster than expected when caddisflies were combined with shrimps or snails, but the increases (23\% with shrimps, $10 \%$ with snails) were not statistically significant. Evidently pair-wise interactions including caddisflies were relatively minor (or too small to be detectable), and most of the nonadditive effects arose from probable facilitation between snails and shrimps. The higher body mass attained by shrimps in multiple-species treatments relative to single-species treatments indicated that shrimp feeding was enhanced both by snails and caddisflies, thereby appearing to confirm the occurrence of facilitation. However, we cannot rule out the possibility that reduction of intraspecific competition amongst shrimps that were mixed with snails and/or caddisflies could have been responsible for the apparent facilitation effect. Greater potential for facilitation by caddisflies may have been limited by pupation of $22 \%$ of larvae during feeding trials. These larvae were replaced rapidly, but onset of pupation would have been preceded by cessation or 
depression of feeding and reduced LML. Consumption of leaf cases by conspecifics, as occurs in Anisocentropus kirramus (Boyero \& Pearson, 2006), would also tend to reduce the magnitude of interspecific facilitation effects of $A$. maculatus caddisflies on shrimps and snails.

We found no evidence of negative non-additive interactions amongst the Hong Kong detritivores, although $12-47 \%$ reductions in per capita LML have been recorded in mixtures combining one or more Australian caddisflies with a leptophlebiid mayfly (Boyero et al., 2007). Whilst the underlying mechanisms are unclear, diversity has been reported to be associated with growth reductions in caddisflies, particularly at higher densities where there is potential for antagonistic interactions or interference (McKie et al., 2008; see also Boyero \& Pearson, 2006) and dominance effects may become influential (Dangles \& Malmqvist, 2004). We attempted to minimize the potential for such interference in this study by ensuring that total detritivore densities remained constant irrespective of increased species richness. These densities (3-5 ind g AFDM litter ${ }^{-1}$ ) were within the lower range of values in the field (1-31 ind $g$ AFDM litter ${ }^{-1}$ in coarse-mesh litter bags: unpublished observations; see also Li et al., 2009).

The occurrence of non-additive compositional effects of three study species suggests that none of them is a redundant member in the detritivore guild in Hong Kong streams, and facilitation was particularly evident in mixtures containing snails and shrimps. We do not know whether leaf shredding by any of the detritivores in this study affects food availability for collector invertebrates, as has been demonstrated by Jonsson \& Malmqvist (2005), but since B. hainanensis snails constitute much of the biomass of the detritivore guild in Hong Kong steams (Li \& Dudgeon, 2008a, 2009), it is conceivable that these snails can influence resource availability for other functional feeding groups. This possibility would be amenable to experimental test. Nonetheless, the occurrence of compositional effects within the detritivore guild confirms the proposition that the effects of species loss on ecosystem function will depend on species identity (Kominoski et al., 2010; see also Lecerf \& Richardson, 2010). Such losses, particularly of 'facilitator' species, could have profound consequences for litter processing in streams that support few detritivores.
Acknowledgements We thank Lily Ng for technical support. The study described in this article was partially supported by a grant from the Research Grants Council of Hong Kong Special Administrative Region, China (Project No. [HKU] 7509/06M).

Open Access This article is distributed under the terms of the Creative Commons Attribution Noncommercial License which permits any noncommercial use, distribution, and reproduction in any medium, provided the original author(s) and source are credited.

\section{References}

Ball, B. A., M. D. Hunter, J. S. Kominoski, C. M. Swan \& M. A. Bradford, 2008. Consequences of non-random species loss for decomposition dynamics: experimental evidence for additive and non-additive effects. Journal of Ecology 96: 303-313.

Boyero, L. \& R. G. Pearson, 2006. Intraspecific interference in a tropical stream detritivore guild. Marine and Freshwater Research 57: 201-206.

Boyero, L., R. G. Pearson \& M. Bastian, 2007. How biological diversity influences ecosystem function: a test with a tropical stream detritivore guild. Ecological Research 22: 551-558.

Cardinale, B. J., D. S. Srivastava, J. E. Duffy, J. P. Wright, A. L. Downing, M. Sankaran \& C. Jousseau, 2006. Effects of biodiversity on the functioning of trophic groups and ecosystems. Nature 443: 989-992.

Covich, A. P., M. C. Austen, F. Bärlocher, E. Chauvet, B. J. Cardinale, C. L. Biles, P. Inchausti, O. Dangles, M. Solan, M. O. Gessner, B. Statzner \& B. R. Moss, 2004. The role of biodiversity in the functioning of freshwater and marine benthic ecosystems. BioScience 54: 767-775.

Dangles, O. \& B. Malmqvist, 2004. Species richness-decomposition relationships depend on species dominance. Ecology Letters 7: 395-402.

Dudgeon, D., 1982. An investigation of physical and biological processing of two species of leaf litter in Tai Po Kau Forest Stream, New Territories, Hong Kong. Archiv für Hydrobiologie 96: 1-32.

Dudgeon, D., A. H. Arthington, M. O. Gessner, Z. Kawabata, D. Knowler, C. Lévêque, R. J. Naiman, A.-H. PrieurRichard, D. Soto, M. L. J. Stiassny \& C. A. Sullivan, 2006. Freshwater biodiversity: importance, threats, status and conservation challenges. Biological Reviews 81: 163182.

Gessner, M. O. \& E. Chauvet, 2002. A case for using litter breakdown to assess functional stream integrity. Ecological Applications 12: 498-510.

Giller, P. S., H. Hillebrand, U.-G. Berninger, M. O. Gessner, S. Hawkins, P. Inchausti, C. Inglis, H. Leslie, B. Malmqvist, M. T. Monaghan, P. J. Morin \& G. O’Mullan, 2004. Biodiversity effects on ecosystem functioning: emerging issues and their experimental test in aquatic environments. Oikos 104: 423-436.

Hooper, D. U., F. S. Chapin, J. J. Ewel, A. Hector, P. Inchausti, S. Lavorel, J. H. Lawton, D. M. Lodge, M. Loreau, S. 
Naeem, B. Schmid, H. Setälä, A. J. Symstad, J. Vandermeer \& D. A. Wardle, 2005. Effects of biodiversity on ecosystem functioning: a consensus of current knowledge. Ecological Monographs 75: 3-35.

Jacobsen, D., C. Cressa, J. M. Mathooko \& D. Dudgeon, 2008. Macroinvertebrates: composition, life histories and production. In Dudgeon, D. (ed.), Tropical Stream Ecology. Academic Press, London: 66-105.

Jonsson, M. \& B. Malmqvist, 2000. Ecosystem process rate increases with animal species richness: evidence from leaf-eating, aquatic insects. Oikos 89: 519-523.

Jonsson, M. \& B. Malmqvist, 2003. Mechanisms behind positive diversity effects on ecosystem functioning: testing the facilitation and interference hypotheses. Oecologia 134: 554-559.

Jonsson, M. \& B. Malmqvist, 2005. Species richness and composition effects in a detrital processing chain. Journal of the North American Benthological Society 24: 798806.

Jonsson, M., B. Malmqvist \& P. O. Hoffsten, 2001. Leaf litter breakdown rates in boreal streams: does shredder species richness matter? Freshwater Biology 46: 161-171.

Jonsson, M., O. Dangles, B. Malmqvist \& F. Guérold, 2002. Simulating species loss following disturbance: assessing the effects on process rates. Proceedings of the Royal Society London B 269: 1047-1052.

Kominoski, J. S., T. J. Hoellein, C. J. Leroy, C. M. Pringle \& C. M. Swan, 2010. Beyond species richness: expanding biodiversity-ecosystem functioning theory in detritusbased streams. River Research and Applications 26: 6775.

Lau, D., K. M. Y. Leung \& D. Dudgeon, 2009. Evidence of rapid shifts in the trophic base of lotic predators using experimental dietary manipulations and assimilationbased analyses. Oecologia 159: 767-776.

Lecerf, A. \& J. S. Richardson, 2010. Biodiversity-ecosystem function research: insights gained from streams. River Research and Applications 26: 45-54.

Li, A. O. Y. \& D. Dudgeon, 2008a. Food resources of shredders and other benthic macroinvertebrates across a range of shading conditions in tropical Hong Kong streams. Freshwater Biology 53: 2011-2025.
Li, A. O. Y. \& D. Dudgeon, 2008b. The effects of leaf litter characteristics on feeding and fitness of a tropical stream shredder. Marine \& Freshwater Research 59: 897-901.

Li, A. O. Y. \& D. Dudgeon, 2009. Shredders: species richness, abundance, and role in litter breakdown in tropical Hong Kong streams. Journal of the North American Benthological Society 28: 167-180.

Li, A. O. Y., L. C. Y. Ng \& D. Dudgeon, 2009. Influence of leaf toughness and nitrogen content on litter breakdown and macroinvertebrates in a tropical stream. Aquatic Sciences 71: 80-93.

Loreau, M., S. Naeem, P. Inchausti, J. Bengtsson, J. P. Grime, A. Hector, D. U. Hooper, M. A. Houston, D. A. Raffaelli, B. Schmid, D. Tilman \& D. A. Wardle, 2001. Biodiversity and ecosystem functioning: current knowledge and future challenges. Science 294: 804-808.

McIntyre, P. B., L. E. Jones, A. S. Flecker \& M. J. Vanni, 2007. Fish extinctions alter nutrient recycling in tropical freshwaters. Proceedings of the National Academy of Sciences 104: 4461-4466.

McKie, B. G., G. Woodward, S. Hladyz, M. Nistorescu, E. Preda, C. Popescu, P. S. Giller \& B. Malmqvist, 2008. Ecosystem functioning in stream assemblages from different regions: contrasting responses to variation in detritivores richness, evenness and density. Journal of Animal Ecology 77: 495-504.

Naeem, S., L. J. Thompson, S. P. Lawler, J. H. Lawton \& R. M. Woodfin, 1994. Declining biodiversity can alter the performance of ecosystems. Nature 368: 734-737.

Schmid, B., A. Hector, M. A. Huston, P. Inchausti, I. Nijs, P. W. Leadley \& D. Tilman, 2002. The design and analysis of biodiversity experiments. In Loreau, N., S. Naeem \& P. Inchausti (eds), Biodiversity and Ecosystem Functioning: Synthesis and Perspectives. Oxford University Press, Oxford: 61-75.

Yam, R. S. W. \& D. Dudgeon, 2006. Production dynamics and growth of atyid shrimps (Decapoda: Caridina spp.) in 4 Hong Kong streams: the effects of site, season, and species. Journal of the North American Benthological Society 25: $406-416$. 